\title{
Integrated Reporting: Development and State of Art — The Italian Case in the International Context
}

\author{
Filippo Vitolla ${ }^{1}$, Nicola Raimo ${ }^{1} \&$ Elbano De Nuccio ${ }^{1}$ \\ ${ }^{1}$ Department of Economics and Management, University LUM Jean Monnet, Italy \\ Correspondence: Filippo Vitolla, Department of Economics and Management, University LUM Jean Monnet, \\ Casamassima (BA), Italy. E-mail: vitolla@lum.it
}

Received: June 30, 2018

Accepted: July 18, 2018

Online Published: October 15, 2018

doi:10.5539/ijbm.v13n11p233

URL: https://doi.org/10.5539/ijbm.v13n11p233

\begin{abstract}
The attention to integrated reporting has more and more increased, since the birth, in 2010 of IIRC, to the present day. This practice, in recent years, is arousing the interest not only of practitioners, but also of academics. In this perspective, the reconstruction of the development process and a series of in-depth analyses on the topic can represent an important source of information for practitioners and a solid basis for future research by academics. This study aims to meet this dual need through a reconstruction of the development process and an analysis of the benefits and of the current state of integrated reporting in the world. The study also presents an important focus on the situation of integrated reporting in Italy by virtue of the recent implementation of Legislative Decree n. 254 of December 30, 2016. This rule provides for the obligation to prepare a non-financial statement starting from the year 2017 and offers many insights on the progress of integrated reporting. The study shows the central, but not unique role of legislation in the adoption and dissemination of integrated reporting.
\end{abstract}

Keywords: integrated reporting, Italian Case, reconstruction of the development process

\section{Introduction}

The history of environmental and social reporting is very long (Guthrie \& Parker, 1989; Buhr, 2007). Initially, these types of disclosure were included in the corporate annual financial reports. However, in the last twenty years, environmental social disclosures have been made in separating and independent reports or through the use of websites (Cho et al., 2009). These reports were more complex and time consuming because they included a wide range of issues to meet the alleged information need from stakeholders. The complexity and length of these reports have shown the need to combine financial and non-financial information. In this view, recent moves have sought to integrate financial, environmental, social and governance information in a single report (Hopwood et al., 2010; Dey \& Burns, 2010). The integration of this information has given rise to so-called integrated reporting. The attention to integrated reporting has more and more increased, since the birth, in 2010 of the International Integrated Reporting Committee, subsequently renamed the International Integrated Reporting Council, to the present day. Integrated reporting, in recent years, is raising the interest not only of practitioners, but also of academics. In this view, the reconstruction of the integrated reporting development process and a series of in-depth analyses on the topic, can represent an important source of information for practitioners and a solid basis for future research by academics. Therefore, this work contributes to the knowledge of the topic through the reconstruction of the development phases, the benefits and the current state of integrated reporting in the world and especially in Italy. The choice of Italy is connected to the recent implementation in the Italian judicial system of the Legislative Decree n. 254 of December 30, 2016, implementing Directive 2014/95 / EU, which regulates the disclosure of non-financial and diversity information by large companies and groups. The introduction of this rule, with the obligation to prepare a non-financial statement starting from the year 2017, offers many insights on the progress of integrated reporting. The second section, through the analysis of the antecedents and the pioneers, examines the process of approaching integrated reporting. The third section analyses, from an internal and external point of view, the benefits associated with the adoption of integrated reporting. The fourth section analyses the current state of integrated reporting in the world while the fifth section focuses on Italy. The last section draws the conclusions.

\section{Towards Integrated Reporting}

In this section we examine the path towards integrated reporting, analysing first the antecedents of integrated reporting and then the pioneers in this field. 


\subsection{Antecedents}

In the last two decades, many researchers have focused on accounting systems for the joint management and reporting of financial and non-financial performance. Most scholars (e.g. Nixon \& Burns, 2012; Giovannoni \& Maraghini, 2013) seem to agree on the identification of three main frameworks that precede integrated reporting: the Balanced Scorecard, the Triple Bottom Line and Sustainability Reporting. The Balanced Scorecard is an internal control, performance measurement and reporting mechanism that includes financial and non-financial measures (Kaplan \& Norton, 1996). This tool, not only is able to overcome the limits of financial indicators, but is also able to align the objectives of individuals or departments with the strategic objectives of the organization as a whole, through the use of tangible measures and outcomes. The choice of measures to be introduced in the Balance Scorecard is related to the strategies of top management and varies from organization to organization. Therefore, very often, these measures do not concern environmental, social or sustainability aspects. The debate regarding the Triple Bottom Line is due to the publication of the book "Cannibals with Forks: The Triple Bottom Line of 21st Century Business" by John Elkington (1997). Unlike the Balance Scorecard, the Triple Bottom Line has a more externally oriented view and suggests the need to disclose information on environmental and social issues (Elkington, 1997). More recently, the tendency has been to combine social and environmental disclosures in sustainability disclosures. However, the term sustainability has met with much criticism. In fact, many academics have pointed out that the term "sustainability disclosure" is only an attempt by organizations to align themselves with the concept of sustainability only in a symbolic and non-substantial way (Milne et al., 2009; Buhr et al., 2014). This criticism also involved the Triple Bottom Line (Brown et al., 2006). The development of integrated reporting seems to be strongly influenced by considerations related to environmental and social reporting. Until the end of the 1990s, many environmental and social disclosures took place through the corporate annual reports. The nature of these corporate annual reports was predominantly financial, however, many organizations have used them to disclose social and environmental information (Unerman, 2000). The decision to introduce such information within the annual reports seems to be due to the desire of management to satisfy the information needs of stakeholders (Neu et al., 1998; Deegan, 2002). The increasing diffusion of environmental and social reports and the increase in the information contained in them have led many organizations to separate environmental and social disclosures, using alternative means to the annual report. In these organizations, the annual report mainly contained information of central importance to their financial stakeholders (De Villiers \& Van Staden, 2011). The information addressed to the other types of stakeholders were instead published in stand-alone environmental and social reports or on websites (De Villiers \& Van Staden, 2011). Simultaneously with the diffusion of stand-alone environmental and social reports, some institutes such as AccountAbility and GRI have introduced initiatives aimed at developing voluntary reporting standards that can guide organizations in implementing these reporting practices. The introduction of these voluntary reporting standards was mainly aimed at improving the credibility and comparability of the reports. The result was an increase in the complexity and length of the reports, which, however, did not guarantee a greater understanding by readers. In fact, very often, readers of a report complying with the GRI standards had difficulty in systematically linking the information contained therein and identifying the links between the different environmental, social and economic impacts. In this perspective, an important innovation was represented by the birth of the Prince's Accounting for Sustainability Project. In fact, one of its objectives was to resolve the issue of disconnection in sustainability reports. In this regard, in 2007, the Prince's Accounting for Sustainability Project developed the so-called "connected reporting", whose main purpose was to provide a balanced representation of the links between economic, social and environmental actions and the outcomes obtained (Hopwood et al., 2010). The aforementioned need to harmonize the various sources of corporate reporting and the desire to bring together the various existing frameworks has led to the creation of an authoritative body aimed at standardizing internationally the principles and criteria for elaborating integrated reporting. In 2010, the Prince's Accounting for Sustainability Project and the GRI formed, together with investors, companies, standard setters, auditors and non-governmental organizations, the IIRC, with the aim of drafting an internationally accepted Framework, which integrates financial and non-financial information, aimed at creating the basis for developing a new model of corporate communication on the process of value creation over time. The assumption was that this communication should represent the new stage to be achieved within the evolutionary path of corporate reporting. The IIRC aimed to improve the quality of information and to create a more cohesive and efficient communication process, based on integrated thinking and the creation of value over time as a means to direct the allocation of resources and the company behaviour towards objectives of economic stability and sustainable development. The formation process ended, after several intermediate stages, with the publication of the definitive version of the International $<\mathrm{IR}>$ Framework in December 2013. This framework established the guiding principles, the contents and the fundamental concepts for the creation of an integrated report, focused on the creation of value in the short, medium and long term, that valorise the conciseness, the strategic focus, the 
orientation to the future, the connectivity of information and capitals and the integrated thinking within the organization. The formation process of the Framework was characterized by the presence of an important initiative, represented by the Pilot Program. It was a project launched in October 2011 that brought together over 100 companies from around the world and belonging to different sectors that had become available to develop, test and share the principles, contents and practical applications of the first forms of IIRC compliant integrated reporting.

\subsection{First Movers in the Integrated Reporting Area}

The study of integrated reporting pioneers includes an analysis at firm level and an analysis at country level. At the firm level, the first organization to prepare an integrated report was Novozymes, a Danish enzyme firm, spin-off of the Novo Nordisk pharmaceutical group. Later it was Novo Nordisk to publish its own integrated report. The reason behind Novo Nordisk's decision to adopt integrated reporting seemed to be linked to the company's aspiration to create a culture of integration in management and measurement. In this perspective, since 2003 Novo Nordisk has started to measure and report economic, environmental and social performance in a single document, becoming a leader in the development of voluntary non-financial disclosures and pioneers of the concept of integrated thinking and embedding of sustainability within business strategy (Dey \& Burns, 2010). At the country level, the first country to strongly introduce the concept of integrated reporting was South Africa. The introduction of integrated reporting in South Africa has its roots in the post apartheid period. In those years, in fact, key elements of the economic and social order were questioned, including the right of companies to make profits (De Villiers \& Van Staden, 2006). This disorder in the country, combined with economic and social inequalities, allowed the Institute of Directors in Southern Africa (IoDSA) to publish the King Reports on Corporate Governance. The first publication, called King I, dates back to 1994. Subsequently, in 2002 King II was published, in 2009 King III and in 2016 King IV. King I highlighted how companies were required to deliver a balanced representation of their reality to the public. King II, added pieces to King I, requiring companies to involve stakeholders in social and environmental issues. Subsequently, King III, by promoting the concept that strategy, governance and sustainability were closely intertwined, urged companies to engage in the principles of integrated reporting. These principles, presented by King III, were subsequently included in the listing requirements of the Johannesburg Stock Exchange, obliging the listed companies prepare the integrated report. King III was effective in South Africa from 1 March 2010 and applied to all entities regardless of the manner incorporation. Currently King III has been replaced by King IV, released in late 2016. King IV has been structured as a framework easily applicable by listed and unlisted, private and public, profit and non-profit companies. It includes further guidance for various categories of organizations and sectors such as small and medium-sized enterprises, public sector organizations and entities, non-profit organizations, pension funds and municipalities. The King IV approach is different from that of King III. In fact, King IV requires an "apply and explain" approach while King III was based on an "apply or explain" approach. King IV, therefore, assumes the application of the principles and requires that an explanation be provided on the implemented practices and on the progress made towards governance outcomes.

\section{Integrated Reporting Benefits}

The reasons that encourage companies to adopt integrated reporting are not exclusively connected to the attention paid to ESG indicators and sustainability issues. Integrated reporting is first and foremost considered a new approach to constantly communicate to all stakeholders the way in which the company creates value. In the current context, where the demand for new leadership models able to align profit research with ESG issues is increasingly felt, the benefits of integrated reporting are considerable. From an internal point of view, the benefits are primarily represented by a greater understanding of long-term performance and, second, by the creation of relationships between financial and non-financial indicators able to allow a better allocation of resources and an optimization of the decision-making processes. From an external point of view, the benefits are mainly connected to the greater involvement of the stakeholders. This allows companies, in the short term, greater involvement by employees, suppliers and customers and, in the long run, greater speed and effectiveness in responding to the expectations of investors who are particularly attentive to ESG issues. The integrated reporting also allows to increase the level of trust of the stakeholders, thanks to its ability to improve the credibility of the company as a source of information. The goal of integrated reporting is to make organizational narrative easily accessible and comprehensible, continuous, with data that is easy to process and use and able to provide a complete picture of the company and its impacts on stakeholders and society.

\section{Integrated Reporting Around the World}

According to the International Integrated Reporting Council, the global adoption of the IIRC framework is in a sharp phase of progress. Other organizations such as GRI and WBCSD show how more and more companies around the world are adopting integrated reporting. As already widely said, South Africa represents the pioneer 
country in the field of integrated reporting and, still today, it is the only country where the disclosure of integrated reporting is a legal requirement for all companies listed on the Johannesburg Stock Exchange. A ranking drawn up by the GRI shows that the leading country, in terms of integrated reporting, is South Africa, followed by the Netherlands, Brazil and Australia. With a view to regions and not to countries, the region most attentive to issues related to integrated reporting is Africa, followed by US, Latin America and Oceania. In the United States, the US Sustainability Accounting Standards Board and the IIRC have reached an agreement to accelerate the adoption of integrated reporting. In Brazil, BM\&FBOVESPA, through its "Report or Explain for Sustainability or Integrated Reporting" initiative, in partnership with the GRI, has encouraged listed companies to embrace integrated reporting. Australia is one of the countries promoting integrated reporting and, although it is applied on a voluntary basis, there are many organizations that adopt it. However, it seems that integrated reporting is gaining ground in other areas of the world, such as some Asian countries including Japan, Singapore, India, China and Malaysia. In Japan, the corporate reporting reform towards the adoption of integrated reporting was supported by the Expert Committee on the Desirable Market Economy System, established by the Council on Economic and Fiscal Policy of Japan. A report by the Expert Committee on the Desirable Market Economy System recommended the use of integrated reporting for Japanese companies. A 2013 survey conducted by the Japan Investor Relations Association underlined how a good number of Japanese organizations had adopted integrated reporting or were planning to do so (JSIF, 2013). In Singapore, the drive towards the adoption of integrated reporting was given by the Singapore Accountancy Commission (SAC), which publicly endorsed the International $<\mathrm{IR}>$ Framework, arguing that its adoption would provide a more complete and coherent picture of the companies that would contribute to greater information transparency. The chief executive of SAC announced the plan for Singapore to become the hub for integrated reporting in Southeast Asia. In India, the Securities and Exchange Board of India asked the first 500 listed companies to prepare integrated reports, while in China, the Ministry of Finance approved the IIRC Framework (Barth et al., 2017). In Malaysia, the Securities Commission Malaysia issued a new corporate governance code in order to encourage companies to adopt integrated reporting. Also in Europe, the attention to integrated reporting is significantly increasing. In France, an important step towards integrated reporting is represented by the Grenelle II law, published on 12 July 2010, which has imposed in the annual reports the inclusion of non-financial information, particularly social and environmental, verified by independent third parties, to all companies, listed and unlisted, public and private, with more than 500 employees. In the United Kingdom, in 2013, an amendment to the Companies Act, concerning the strategic report and the directors' report, required all listed companies to prepare a strategic report separate from the annual report, more detailed and transparent, containing information on risks, business strategy and social and environmental issues. In Germany, German Accounting Standard 15 represents a push towards integrated reporting, requiring information on the context, KPIs, risks and opportunities, corporate governance and future prospects. In Sweden, state-controlled companies must publish annual reports in compliance with the GRI principles. In Norway, national legislation on non-financial disclosure imitates the objectives of the $<\mathrm{IR}>$ framework. In fact, large companies are obliged to provide information on how they integrate social responsibility into their business strategy. In Denmark, an important step towards integrated reporting is represented by the "Act amending the Danish Financial Statements Act" of 2008, which requires larger companies, listed companies and public companies to report on sustainability performance. In Finland, there is no formal legislation on non-financial disclosure, but the government has adopted a resolution that requires non-listed state-owned firms to report on their CSR policies.

\section{The State of Integrated Reporting in Italy}

In their survey on the role of integrated reporting in Italy, Gesuele and Pozzoli (2017) underline two main objectives of what they consider to be the last frontier of corporate communication. The first objective, in line with the provisions of the IIRC Framework, is to combine financial and non-financial information in order to stimulate a stakeholder judgment on performance and value creation over time. The second objective is related to legitimacy and empowerment. In fact, in this perspective, integrated reporting is able to guide management and provide evidence of positive business results. Despite the wide debate, a study by Camodeca and Almici (2017) highlighted how, in Italy, only six companies listed on 338 adopted integrated reporting. However, this situation seems to have changed due to the entry into force of a new law, the Legislative Decree n. 254 of December 30, 2016, which represents the implementation of Directive 2014/95 / EU. This directive, which modifies Directive $2013 / 34$ / EU, wanted to recognize a role of greater relevance to non-financial information. It is addressed to large companies that constitute public interest entities and which, at the closing date of the financial statements, have a number of employees employed on average during the year equal to 500. Directive 2014/95 / EU seems to affect about 6000 companies (Vitolla et al., 2018). In compliance with the Directive, Legislative Decree n. 254 of December 30, 2016 is aimed at parent companies of a large group and companies that, in addition to having employees for a number of not less than 500 , have exceeded, at the closing date of the financial statements, at least 
one of the following two limits:

- €20.000.000 of balance sheet;

- €40.000.000 of net revenue.

In the first hypothesis, the report will be consolidated and will also include data on parent companies and subsidiaries. On the contrary, in the second hypothesis, the company will be required to prepare an individual non-financial statement. Pursuant to Legislative Decree n. 254 of 30 December 2016, the non-financial report must ensure the understanding of the company's activities, performance and management impact. It must also cover environmental and social issues, those relating to employee, to the respect for human rights and to the fight against active and passive corruption, describing at least:

- The business model for the management and organization of business activities;

- The policies practiced by the company, including due diligence, the results achieved and the related non-financial indicators;

- The main risks arising from or arising out of the aforementioned issues deriving from the business activities, from its products, services or business relationships, including, where relevant, supply chains and subcontracts.

Therefore, the non-financial statement must contain specific references to the energy consumption with a mandatory distinction between those produced from renewable and non-renewable sources and the clarification of the use of water resources. Furthermore, the non-financial statement must describe the emissions of greenhouse gases and pollutant emissions into the atmosphere. It must also indicate the impact on the environment, on health and safety, or other environmental and health risk factors. The non-financial statement must also provide a report on social aspects and the management of employees with actions aimed at ensuring gender equality and the implementation of international conventions on the matter. The non-financial report must also indicate the implementing rules of the dialogue between the social partners and respect for human rights. Finally, companies must indicate the instruments adopted to combat both active and passive corruption. Clearly, the selection of relevant information must always be based on the principle of materiality and therefore on an analysis of the specificities of each company. In this view, information should be provided only to the extent that such indications are significant in light of the activity carried out by the company and its characteristics. The information contained in the non-financial statement must be compared with those of the previous year with regard to the same indicators and with the methods and principles set out in the reporting standard used. One of the most complex challenges for companies is represented by the choice of key indicators. Taking the training as an example, De Colle et al. (2014) show how the number of hours per worker may not be a valid indicator because it does not take into account the quality of teaching and the improvements in knowledge. Regarding the positioning and, consequently, the visibility of the statement, there are two different solutions. The former provides inclusion in the management report, while the second solution is represented by the creation of a separate report. Although there is the possibility of choosing between the two solutions, it is clear that a certain conformity in the choice is necessary in order to easily allow the consultation of the document to all the stakeholders. The non-financial report must be published, after approval by the board of directors, together with the management report, in the Business Register. This shows the clear will to go towards integration and to avoid the dispersion of data, and physical or temporal gaps. The simultaneous publication also allows the connection between the non-financial report and the management report and, consequently, allows to constantly track the results achieved. The non-financial statement is also subject to a statutory audit for the purpose of attesting the conformity of the information provided with respect to the provisions of the Decree and the declared principles, methods and reporting standards. With regard to the latter, the legislative decree admits the standards and guidelines issued by supranational, international or national bodies of a public or private nature to the extent that they are in compliance with the European directive. It is also possible for organizations to apply an independent reporting methodology represented by a set composed of one or more reporting standards and any other freely established criteria, principles and performance indicators. It is evident, however, that IR is a candidate for being the main reference standard, since it is able to allow companies to be perfectly compliant with the Decree. Another interesting aspect related to the Legislative Decree concerns SMEs. In fact, while the European disclosure requirements apply only to large companies and groups, the legislative decree offers integrated reporting opportunity also to SMEs. In fact, the Legislative Decree offers the opportunity to subjects other than those included in the field of application, which on a voluntary basis prepare and publish individual or consolidated non-financial statements, in compliance with the decree, to insert the declaration of conformity to the decree. Considering the large presence of SMEs in Italy, this opportunity potentially extends the objectives of the Legislative Decree considerably. In fact, the inclusion of SMEs within the field of application, even if only on a voluntary basis, promotes the dissemination of the culture related to 
integrated thinking and the identification of specific reporting models and solutions that may also be useful for large companies and groups. The Legislative Decree therefore represents an important innovation in the field of corporate reporting. Indeed, following its entry into force, a series of previously voluntary information has become mandatory. However, innovation is not confined to the strict scope of corporate reporting but also has an important impact on the evolution of managerial practices. For example, the legislator's request for information regarding the main risks involves the implementation by companies of a risk management system. In this regard, therefore, the Legislative Decree is a formidable lever for the evolution and dissemination of best practices and it is able to foster a virtuous process. In fact, on the one hand the Legislative Decree obliges companies to adopt best practices, on the other hand, investors will get more useful information and then exert pressure on all other companies to provide the same set of information. It is clear that, following the entry into force of the Legislative Decree, reporting is no longer just a simple exercise of compliance, but represents the last piece of a broad and organic process that, starting from the collection and validation of data, allows the representation of all aspects of the activity business in an holistic vision. In this way, sustainability no longer represents a separate concept, but actually enters into the perimeter of the top management, favouring a vision of development of the company increasingly attentive to ESG issues. One of the main challenges that Italian companies will have to answer when implementing the new law is to understand how to better capitalize the processes already carried out with reference to both risk management and social responsibility. However, regardless of how the companies organize themselves in order to draft the non-financial statement, the Legislative Decree favour a collaborative and constructive dialogue between the various company departments involved. However, as for the limits, the Legislative Decree seems to leave many interpretative doubts. In fact, by not providing indications on the process of identification and evaluation of all social and environmental aspects, it leaves on one side a certain flexibility, but on the other it generates uncertainty. Furthermore, the Legislative Decree does not provide an explicit definition of what information should be considered material, leaving the companies at the mercy of a vast amount of information that can be potentially reported. In general, a shared operational guideline on how to move from theory to practice appears to be absent.

\section{Conclusions}

The current global scenario requires a greater contribution of companies to the construction and maintenance of well-being, through the repositioning of their role within society. The growing attention to social and environmental issues, together with the growing need for transparency of companies, requires, in fact, new corporate reporting actions. In this view, integrated reporting is a key solution for its ability to give a central role to the stakeholders and to integrate all aspects related to the business activity and the value creation. The purpose of our article was to provide a study on the subject of integrated reporting, able to represent a solid basis for future research by academics and an important source of information for practitioners. To this end, we first analysed the development process of integrated reporting starting from the analysis of the antecedents and then we analysed the pioneers and the benefits associated with this practice. In the last two sections we have focused on the current state of integrated reporting in the world and especially in Italy. In light of what has emerged from our study, it appears that legislations play a central role in the adoption and dissemination of integrated reporting. However, legislations do not favor the process of top management change towards the vision of integrated thinking and, on the contrary, they make companies see integrated reporting as a simple legislative imposition (Vitolla, 2007; Vitolla et al., 2016). For this reason, the real challenge connected to the development of integrated reporting is represented by the creation of appropriate values in the top management that can lead to a common and convinced adoption of this practice (Vitolla et al., 2017). Companies should see integrated reporting not as a mere piece of legislation, a burden or an additional duty that increases costs, but as a new approach to creating value in the future, in a positive discontinuity from the past. Therefore, integrated reporting should represent a sense-making tool in line with current and future needs.

\section{References}

Barth, M. E., Cahan, S. F., Chen, L., \& Venter, E. R. (2017). The economic consequences associated with integrated report quality: Capital market and real effects. Accounting, Organizations and Society, 62, 43-64. https://doi.org/10.1016/j.aos.2017.08.005

Brown, D., Dillard, J. F., \& Marshall, S. (2006). Triple bottom line: a business metaphor for a social construct.

Buhr, N. (2007). Sustainability Reporting: History/Rationales. In Unerman, J., Bebbington, J. \& O’Dwyer (Eds.), Sustainability Accounting and Accountability. London: Routledge.

Buhr, N., Milne, M. J., \& Gray, R. (2014). Histories, rationales, voluntary standards and future prospects for sustainability reporting: CSR, GRI, IIRC and beyond. In Sustainability accounting and accountability (2nd ed. pp. 51-71). London: Routledge. 
Camodeca, R., \& Almici, A. (2017). Implementing Integrated Reporting: Case Studies from the Italian Listed Companies. Accounting and Finance Research, 6(2), 121. https://doi.org/10.5430/afr.v6n2p121

Cho, C. H., Phillips, J. R., Hageman, A. M., \& Patten, D. M. (2009). Media richness, user trust, and perceptions of corporate social responsibility: An experimental investigation of visual web site disclosures. Accounting, Auditing \& Accountability Journal, 22(6), 933-952. https://doi.org/10.1108/09513570910980481

De Colle, S., Henriques, A., \& Sarasvathy, S. (2014). The paradox of corporate social responsibility standards. Journal of Business Ethics, 125(2), 177-191. https://doi.org/10.1007/s10551-013-1912-y

De Villiers, C., \& Van Staden, C. J. (2006). Can less environmental disclosure have a legitimising effect? Evidence from Africa. Accounting, organizations and society, 31(8), 763-781. https://doi.org/10.1016/j.aos.2006.03.001

De Villiers, C., \& Van Staden, C. J. (2011). Where firms choose to disclose voluntary environmental information. Journal of Accounting and Public Policy, 30(6), 504-525. https://doi.org/10.1016/j.jaccpubpol.2011.03.005

Deegan, C. (2002). Introduction: The legitimising effect of social and environmental disclosures-a theoretical foundation. Accounting. Auditing \& Accountability Journal, 15(3), 282-311. https://doi.org/10.1108/09513570210435852

Dey, C., Burns, J., Hopwood, A., Unerman, J., \& Fries, J. (2010). Integrated reporting at Novo Nordisk. Accounting for Sustainability: Practical Insights, 197-214.

Elkington, J. (1997). Cannibals with forks: The triple bottom line of twenty-first century business. Capstone.

Gesuele, B., \& Pozzoli, M. (2017). L'utilizzo del Integrated Reporting in Italia. Economia Aziendale Online $2000 \mathrm{Web}, 8(2), 119-129$.

Giovannoni, E., \& Pia Maraghini, M. (2013). The challenges of integrated performance measurement systems: Integrating mechanisms for integrated measures. Accounting, Auditing \& Accountability Journal, 26(6), 978-1008. https://doi.org/10.1108/AAAJ-04-2013-1312

Guthrie, J., \& Parker, L. D. (1989). Corporate social reporting: a rebuttal of legitimacy theory. Accounting and business research, 19(76), 343-352. https://doi.org/10.1080/00014788.1989.9728863

Hopwood, A. G., Unerman, J., \& Fries, J. (2010). Accounting for sustainability: Practical insights. Earthscan. https://doi.org/10.4324/9781849776332

JSIF. (2013), Pension Funds and ESG Investment in Japan 2013. Retrieved from http://media.wix.com/ugd/ebcda8_9f9f5597801b457c8aa8ce6e2fe7ecaa.pdf

Kaplan, R. S., \& Norton, D. P. (1996). The balanced scorecard: translating strategy into action. Harvard Business Press.

Milne, M. J., Tregidga, H., \& Walton, S. (2009). Words not actions! The ideological role of sustainable development reporting. Accounting, Auditing \& Accountability Journal, 22(8), 1211-1257. https://doi.org/10.1108/09513570910999292

Neu, D., Warsame, H., \& Pedwell, K. (1998). Managing public impressions: Environmental disclosures in annual reports. Accounting, Organizations and Society, 23(3), 265-282. https://doi.org/10.1016/S0361-3682(97)00008-1

Nixon, B., \& Burns, J. (2012). The paradox of strategic management accounting. Management Accounting Research, 23(4), 229-244. https://doi.org/10.1016/j.mar.2012.09.004

Unerman, J. (2000). Methodological issues-Reflections on quantification in corporate social reporting content analysis. Accounting, Auditing \& Accountability Journal, 13(5), 667-681. https://doi.org/10.1108/09513570010353756

Vitolla, F. (2007). Le linee guida della Global Reporting Initiative per la redazione dei report di sostenibilità. Rivista dei Dottori Commercialisti, 58(4), 663-690. https://doi.org/10.1108/JMD-08-2015-0113

Vitolla, F., Rubino, M., \& De Nuccio E. (2018). The inverted U-shaped relationship between company size and reporting quality: The Italian case. Corporate Ownership \& Control, 15(3), 114-124.

Vitolla, F., Rubino, M., \& Garzoni A. (2016). Integrated corporate social responsibility: Driving factors and means of integration - a multiple case study analysis. Journal of Management Development, 35(10), $1323-1343$ 
Vitolla, F., Rubino, M., \& Garzoni A. (2017). The integration of CSR into strategic management: A dynamic approach based on social management philosophy. Corporate Governance: The International Journal of Business in Society, 17(1), 89-116. https://doi.org/10.1108/CG-03-2016-0064

\section{Copyrights}

Copyright for this article is retained by the author(s), with first publication rights granted to the journal.

This is an open-access article distributed under the terms and conditions of the Creative Commons Attribution license (http://creativecommons.org/licenses/by/4.0/). 